Editorial

\title{
Double Blind Peer-Review in Humanities
}

\author{
Martyn Rittman ${ }^{1}$ and Albrecht Classen ${ }^{2}$ \\ Received: 22 December 2015; Accepted: 22 December 2015; Published: 23 December 2015 \\ 1 MDPI AG, Klybeckstrasse 64, CH-4057 Basel, Switzerland; rittman@mdpi.com \\ 2 Department of German Studies, University of Arizona, Tucson, AZ 85721, USA; \\ aclassen@email.arizona.edu
}

Pre-publication peer-review forms the basis of how scholarly journals assess whether an article is suitable for publication. It is of paramount importance that the process is perceived to be fair, robust, and free of bias. One of the key methods for achieving this goals is using a blind-reviewing method. Up until now, Humanities has used a single blind peer-review approach, where the reviewer identities are not known to authors. This allows reviewers to submit honest opinions without fear that their comments will be used against them in another context. Journal editors take responsibility for the final acceptance decision, taking into account the reports provided by expert reviewers in the field.

In a single-blind process, however, authors may feel that they are not fairly treated. There is the suspicion that a renowned figure may be given an easy ride by reviewers, or that a young scholar is considered too inexperienced to assert his or her opinion. In an ideal peer-review process, we must avoid all types of biases ranging from the unconscious to the blatant prejudice. While we trust that our reviewers fulfil this aim to the best of their abilities, is it possible to do more?

We have decided to move Humanities to a double blind peer-review process. For papers submitted after 31 December 2015, reviewers will no longer be informed of the names of the authors who have submitted a manuscript until a final decision has been made. We believe that this decision will reduce bias and particularly help emerging scholars to receive a fair review. We are aware that no system is perfect, and there are always some doubts about the extent to which even double blind review solves the problem of bias. However, our aim is to demonstrate a commitment to robust, independent and fair reviews.

We would like to take this opportunity to thank all the past and present anonymous reviewers who have contributed to this peer-reviewing process and continue to make this a first-rate scholarly journal. Their voluntary contributions, based on their experiences in the respective field, help us to maintain a high standard in our published papers and underpins our editorial process.

Conflicts of Interest: The authors declare no conflict of interest.

(C) 2015 by the authors; licensee MDPI, Basel, Switzerland. This article is an open access article distributed under the terms and conditions of the Creative Commons by Attribution (CC-BY) license (http://creativecommons.org/licenses/by/4.0/). 